\title{
Comparison between two solute equations and bioimpedance for estimation of body fluid volumes
}

\author{
Robert G. Hahn ${ }^{1,2^{*}}$ and Marc Giménez-Milà 3,4,5 (B)
}

\author{
*Correspondence: \\ robert.hahn@ki.se \\ ${ }^{1}$ Research Unit, Department \\ of Anesthesia \& Intensive \\ Care, Södertälje Hospital, 152 \\ 86 Södertälje, Sweden \\ ${ }^{2}$ Karolinska Institutet \\ at Danderyds Hospital (KIDS), \\ Stockholm, Sweden \\ ${ }^{3}$ Department \\ of Anaesthesiology, "CLINIC de \\ Barcelona" Hospital, University \\ of Barcelona (UB), Carrer Villaroel \\ 170, 08036 Barcelona, Spain \\ ${ }^{4}$ Systems Pharmacology Effect \\ Control and Modeling (SPEC-M) \\ Research Group, "CLINIC de \\ Barcelona" Hospital, Barcelona, \\ Spain \\ 5 "Institut d'Investigacions \\ Biomèdiques August Pi i Sunyer \\ (IDIBAPS)", Barcelona, Spain
}

\begin{abstract}
Background: The extracellular volume (ECV) and intracellular volume (ICV) estimated by bioimpedance analysis (BIA) deviates markedly from the textbook volumes of $20 \%$ and $40 \%$ of the body weight (BW). We estimated the transcellular exchange of water by calculating solute equilibriums after fluid challenges to examine whether the BIA or the textbook volumes are likely to be most correct.

Methods: Data was retrieved from 8 healthy male volunteers who received $25 \mathrm{~mL} /$ $\mathrm{kg}$ of Ringer's solution or 3-5 mL/kg of hypertonic (7.5\%) saline over 30 min after the ECV and ICV had been estimated by BIA. The exchange of water between the ECV and the ICV was calculated according to a sodium equation and an osmolality equation. Simulations were performed, where deviating body fluid volumes were applied.

Results: The mean ECV measured with BIA was $24.9 \%$ of BW ( $p<0.05$ versus the "textbook" volume). Mean ICV measured with BIA was $22.3 \%$ of BW $(p<0.05)$. The sodium and osmolality equations correlated closely with respect to the translocation of water across the cell membrane $\left(r^{2}=0.86\right)$. By applying the "textbook" $E C V$, the sodium equation indicated that Ringer's solution exchanged negligible amounts of water, while hypertonic saline withdrew 1.4 L from the ICV to the ECV. By contrast, applying the BIAderived ECV to the sodium equation implied that $3 \mathrm{~L}$ of water would be translocated from the ECV to the ICV once hypertonic saline was administered.
\end{abstract}

Conclusion: The "textbook" ECV and ICV volumes but not the BIA-derived volumes were consistent with the fluid shifts obtained by two solute equations.

Keywords: Fluid exchange, Bioimpedance analysis, Crystalloids, Mass balance equations

\section{Introduction}

The body fluids are traditionally divided into an extracellular volume (ECV) and an intracellular volume (ICV). Medical textbooks teach that the ECV represents $20 \%$ of the body weight (BW), while ICV corresponds to $40 \%$ of the BW based on indicator-dilution techniques [1-3].

These fractions have been challenged by studies, where electric bioimpedance analysis (BIA) has been applied. The software used with the BIA is calibrated using isotope priate credit to the original author(s) and the source, provide a link to the Creative Commons licence, and indicate if changes were made. The images or other third party material in this article are included in the article's Creative Commons licence, unless indicated otherwise in a credit line to the material. If material is not included in the article's Creative Commons licence and your intended use is not permitted by statutory regulation or exceeds the permitted use, you will need to obtain permission directly from the copyright holder. To view a copy of this licence, visit http://creativecommons.org/licenses/by/4.0/. 
methods [4-6] but the obtained values differ from the "textbook volumes" [7]. The typical finding with BIA is that the ECV is larger than $20 \%$ and that the ICV is smaller than expected, making the ECV:ICV ratio to be 1:1.5 instead of 1:2 [8-12]. It is unclear whether the textbook volumes or the BIA-derived volumes are correct.

In the present work, we study the usefulness of mass balance equations to examine whether a reported body fluid size is reasonable or more likely to be erroneous. For this purpose, we applied a sodium and an osmolality equation that are dependent on correct sizes of the ECV and ICV to estimate the transcellular shift of water after a fluid challenge [13, 14]. The composition and amount of fluid administered determine direction and volume of fluid exchange, which are fairly well known for the literature. However, the relevance of using fluid shift calculations as a quality control of reported body volumes has never been studied.

A comparison between the "textbook volumes" and those reported by BIA served as an example. We used data obtained during experiments in volunteers, where BIA had been measured and isotonic and hypertonic electrolyte fluids were infused in volunteers $[14,15]$.

\section{Methods}

The report is a retrospective analysis of two prospective studies of hemodilution during fluid therapy in volunteers. The protocols had been approved by the Ethics Committee of Huddinge University Hospital (Dnr 228/98 and 54/95, Chairmen Ola Eiken and Lennart Kaijser) $[14,15]$. Informed consent was obtained from all participants. Data was treated according to confidentiality guidance. The studies originally comprised $80 \mathrm{infu}$ sions of both isotonic and hypertonic fluids, but we only used the subset of 15 experiments collected when the 8 volunteers were euvolemic and all data necessary for the evaluation was present.

\section{Procedure and measurements}

The volunteers had a light breakfast consisting of one glass of water or milk and one sandwich at least $2 \mathrm{~h}$ before the infusion. They voided and were weighed just before the infusion started. A recumbent equilibration period of $30 \mathrm{~min}$ was allowed before the experiments were initiated.

The infusions were $20-25 \mathrm{~mL} / \mathrm{kg}$ of nearly isotonic crystalloid fluid either Ringer's lactate or acetate (Ringer group) or $5 \mathrm{~mL} / \mathrm{kg}$ of $7.5 \%$ (hypertonic) saline or $3 \mathrm{~mL} / \mathrm{kg}$ of $7.5 \%$ saline in 6\% dextran (Hypertonic group). All infusions were administered at a constant rate over 30 min using infusion pump. Volunteers received both types of infusion. The washout period between the experiments was at least 1 week.

Blood samples were drawn just before the infusions started, at the end of the infusions (at $30 \mathrm{~min}$ ), and at $240 \mathrm{~min}$. They were analyzed for the serum sodium and the serum osmolality at the hospital's certified clinical chemistry laboratory. The urinary excretion was measured at $240 \mathrm{~min}$ and taken into consideration for sodium and osmolality equation calculation at that point in time. Hence, any adjustment of the fluid shifts indicated by the osmolality equation at $30 \mathrm{~min}$ and $240 \mathrm{~min}$ was solely due to urinary losses of water and osmolality. By contrast, the sodium equation considered measurements of serum sodium both at $30 \mathrm{~min}$ and $240 \mathrm{~min}$ in addition to urinary losses at $240 \mathrm{~min}$. 
Sodium was analyzed by an ion-selective, direct potentiometry technique using an IL BGE analyzer (Instrumentation Laboratory, Milan, Italy) with a coefficient of variation of between 1 and 2\%. Osmolality was measured by an Osmometer 3C2 (Advanced Instruments Inc., Norwood, MA) which is based on freezing-point depression. The CV was approximately $1 \%$.

The size of the ECV and the ICV were estimated by multi-frequency bioelectrical impedance (Xitron 4000B Bioimpedance Spectrum Analyzer, Xitron Technologies Inc., San Diego, CA) just before each infusion was initiated. The software calculates these volumes based on a series of 50 currents of different frequencies between electrodes affixed to the dorsum of one hand and one foot. The mean of three consecutive measurements was used.

\section{Calculations}

The diffusion of fluid into and out of the cells (fluid shift) was calculated by both a sodium equation and an osmolality equation.

The sodium equation is based on a mass balance concept implying that sodium ions (Na) and water in the ECV remain constant over time except for additions and losses. All these additions and losses are known except for fluid exchange between the ECV and ICV spaces. Since Na is distributed throughout the ECV space, the serum Na concentration at any time $(T)$ during or after an intravenous infusion of fluid $\left(\mathrm{Na}_{T}\right)$ equals the amount of $\mathrm{Na}$ in the ECV volume divided by the current ECF volume.

The serum concentration before the intervention, $\mathrm{Na}_{0}$, and at any time $t$ after it has occurred, $\mathrm{Na}_{T}$ are then connected in the following equation [13]:

$$
\text { Fluid exchange }=\mathrm{ECV}_{\mathrm{o}}+\text { infused volume }-\left[\left(\mathrm{Na}_{\mathrm{o}} \mathrm{ECV}_{\mathrm{o}}+\text { infused } \mathrm{Na}\right) / \mathrm{Na}_{T}\right]
$$

If urinary excretion has occurred, the voided volume should be subtracted from the infused fluid volume. Similarly, the sodium ions excreted in the urine should be subtracted from the infused amount of sodium. The positive and negative signs in the sodium equation were inverted to enable comparison between equations.

The osmolality equation is built on the fact that the osmolality is always the same in the ECV and ICV. Hence, we can derive [14]:

$$
\frac{\text { ECF } \cdot \text { S-osmolality start }+ \text { infused osmoles }}{\text { ECF }+ \text { fluid exchnage }+ \text { infused volume }}=\frac{\text { ICF } \cdot \text { S-osmolality start }}{\text { ICF }- \text { fluid exchange }}
$$

This mass balance equation implies that the amount of solutes divided by the fluid volume must remain the same after manipulation of any of involved factors. The only unknown factor in this equation is "fluid exchange" if we assume that the ECV amounts to $20 \%$ of the BW and ICV to $40 \%$ of the BW. Note that no second blood sample is needed. A positive sign in fluid shift of both equations indicates transfer from ICV to ECV.

\section{Statistics}

Data is presented as the mean and standard deviation (SD). The relationship between fluid shift according to different equations was evaluated by simple linear regression 
analysis, where $r^{2}=$ coefficient of determination. The Student's $t$ test was used to compare the "text-book" body fluid volumes with those obtained by BIA. Data analysis was carried out using the $\mathrm{R}$ statistical programming environment (version 3.5 for windows, $\mathrm{R}$ Core Team, 2015). $p<0.05$ was considered statistically significant.

\section{Results}

Demographic and body fluid data

A complete data set was obtained from 15 experiments that were performed in eight male volunteers with a mean age (SD) of 32 (8) years and with a BW of $82(9) \mathrm{kg}$. Three volunteers received Ringer's lactate and three Ringer's acetate (Ringer group), while 7.5\% saline was given to two individuals and $7.5 \%$ saline in $6 \%$ dextran 70 dextran to seven volunteers (Hypertonic group).

The ECV measured with BIA was $20.4 \mathrm{~L}$ ( $24.9 \%$ of BW), which is $4 \mathrm{~L}$ more than given by the widely assumed fraction of $20 \%$ of the BW $(p<0.05)$. Mean ICV measured with BIA was $18.5 \mathrm{~L}(22.3 \%$ of BW), which is significantly smaller than the assumed $32.5 \mathrm{~L}$ based on $40 \%$ of BW $(p<0.05)$.

Table 1 depicts the measured and theoretically assumed ECV and ICV for each experiment and fluid group.

Table 2 shows the infused and excreted amounts of fluid and electrolytes for each experiment and fluid group. The mean (SD) initial serum osmolality was 293.0 (2.2) $\mathrm{mOsm} / \mathrm{kg}$ and serum sodium 140.8 (1.7) $\mathrm{mmol} / \mathrm{L}$. The mean volume (SD) infused in the Ringer group was $1.95(0.08) \mathrm{L}$ and in the hypertonic group $0.28(0.08) \mathrm{L}$. The hypertonic infusions administered $37 \%$ more sodium than the Ringer group, but the

Table 1 Body weight, BIA, and theoretically assumed ECV and ICV for each experiment and fluid group

Body weight (kg) BIA ECV (L) BIA ICV (L) Assumed ECV (L) Assumed ICV (L)

\begin{tabular}{|c|c|c|c|c|c|}
\hline \multicolumn{6}{|l|}{ Hypertonic group } \\
\hline 1 & 78 & 23.5 & 20.3 & 15.6 & 31.2 \\
\hline 2 & 70 & 18.1 & 17.2 & 14 & 28 \\
\hline 3 & 95 & 23.3 & 21.5 & 19 & 38 \\
\hline 4 & 72 & 18.1 & 16.6 & 14.4 & 28.8 \\
\hline 5 & 90 & 18.8 & 15.3 & 18 & 36 \\
\hline 6 & 88 & 21 & 16 & 17.6 & 35.1 \\
\hline 7 & 76 & 19.4 & 16.1 & 15.2 & 30.4 \\
\hline 8 & 72 & 17.6 & 17.5 & 14.4 & 28.8 \\
\hline 9 & 79 & 19.8 & 19.6 & 15.8 & 31.6 \\
\hline Mean (SD) & $81.9(10.1)$ & $19.9(2.2)$ & $17.7(2.1)$ & $16(1.7)$ & $31.9(3.5)$ \\
\hline \multicolumn{6}{|l|}{ Ringer group } \\
\hline 10 & 93 & 23 & 20.38 & 18.6 & 37.2 \\
\hline 11 & 93 & 22.6 & 20.25 & 18.6 & 37.2 \\
\hline 12 & 80 & 21.9 & 20.58 & 16 & 32 \\
\hline 13 & 80 & 21.3 & 21.02 & 16 & 32 \\
\hline 14 & 72 & 17.6 & 17.8 & 14.4 & 28.8 \\
\hline 15 & 79 & 20.6 & 18.04 & 15.8 & 31.6 \\
\hline Mean (SD) & $82.8(8.0)$ & $21.2(1.9)$ & $19.6(1.3)$ & $16.5(1.6)$ & $33.1(3.3)$ \\
\hline Mean of both groups (SD) & $82.1(8.8)$ & $20.4(2.2)$ & $18.5(2.0)$ & $16.2(1.7)$ & $32.4(3.4)$ \\
\hline
\end{tabular}


Table 2 Infused and excreted amounts of fluid and electrolytes for each experiment and fluid group

\begin{tabular}{|c|c|c|c|c|c|c|}
\hline & $\begin{array}{l}\text { Infused volume } \\
(\mathrm{mL})\end{array}$ & $\begin{array}{l}\text { Infused } \\
\text { osmoles } \\
\text { (mOsm) }\end{array}$ & $\begin{array}{l}\text { Infused } \\
\text { sodium } \\
\text { (mmol) }\end{array}$ & $\begin{array}{l}\text { Excreted } \\
\text { volume } \\
(\mathrm{mL})\end{array}$ & $\begin{array}{l}\text { Excreted } \\
\text { osmoles } \\
\text { (mOsm) }\end{array}$ & $\begin{array}{l}\text { Excreted } \\
\text { sodium } \\
\text { (mmol) }\end{array}$ \\
\hline \multicolumn{7}{|c|}{ Hypertonic group } \\
\hline 1 & 234 & 600 & 296 & 750 & 595 & 213 \\
\hline 2 & 210 & 539 & 266 & 700 & 606 & 210 \\
\hline 3 & 285 & 731 & 361 & 800 & 586 & 183 \\
\hline 4 & 216 & 554 & 274 & 240 & 188 & 63 \\
\hline 5 & 270 & 693 & 342 & 850 & 501 & 190 \\
\hline 6 & 228 & 585 & 289 & 950 & 536 & 181 \\
\hline 7 & 440 & 1128 & 556 & 900 & 656 & 190 \\
\hline 8 & 360 & 924 & 456 & 400 & 374 & 118 \\
\hline 9 & 237 & 608 & 300 & 975 & 712 & 205 \\
\hline Mean (SD) & $275(77)$ & 707 (198) & $348(98)$ & 726 (269) & $528(160)$ & $173(50)$ \\
\hline \multicolumn{7}{|c|}{ Ringer group } \\
\hline 10 & 1975 & 543 & 257 & 1100 & 306 & 87 \\
\hline 11 & 1975 & 543 & 257 & 300 & 133 & 38 \\
\hline 12 & 2000 & 550 & 260 & 1100 & 329 & 78 \\
\hline 13 & 2000 & 550 & 260 & 600 & 123 & 53 \\
\hline 14 & 1800 & 495 & 234 & 900 & 455 & 156 \\
\hline 15 & 1975 & 543 & 257 & 1200 & 347 & 79 \\
\hline Mean (SD) & 1950 (716) & $537(21)$ & $254(10)$ & $866(350)$ & $282(130)$ & $82(41)$ \\
\hline
\end{tabular}

excretion differed by $110 \%(p=0.002)$. Similarly, $87 \%$ more osmoles were excreted compared to the Ringer group $(p<0.01)$, while the excreted fluid volumes did not differ $(p=0.39)$.

\section{Fluid transfer across the cell membrane}

The osmolality equation indicated that the transfer of water across the cell membrane in the Ringer group amounted to $-72(10) \mathrm{mL}$ at $30 \mathrm{~min}$ and to -183 (174) $\mathrm{mL}$ at $240 \mathrm{~min}$. The corresponding values according to the sodium equation were - 194 (9) $\mathrm{mL}$ and +198 (104) $\mathrm{mL}$, respectively.

In the Hypertonic group fluid recruitment derived by the osmolality equation was +1355 (595) $\mathrm{mL}$ at $30 \mathrm{~min}$ and $+694(404) \mathrm{mL}$ at $240 \mathrm{~min}$. When based on the sodium equation the fluid transfer amounted to $+1212(385) \mathrm{mL}$ and +1178 (466) $\mathrm{mL}$.

The urinary losses of solutes and water were considered in the calculation at $240 \mathrm{~min}$ but these data were not available at $30 \mathrm{~min}$.

Figure 1 illustrates how the estimated fluid transfer compares between the two equations when based on the assumed ECV and ICV of $20 \%$ and $40 \%$ of BW, respectively.

Figure 2 illustrates the displacement of the data that occurs when the excreted fluid, sodium, and osmolality has been incorporated into the equations at $240 \mathrm{~min}$ (no measurement of losses are available at $30 \mathrm{~min}$ ).

The mean difference between the output of the osmolality and the sodium equation was $-153 \mathrm{~mL}$ (SD $350 \mathrm{~mL}$ ). 


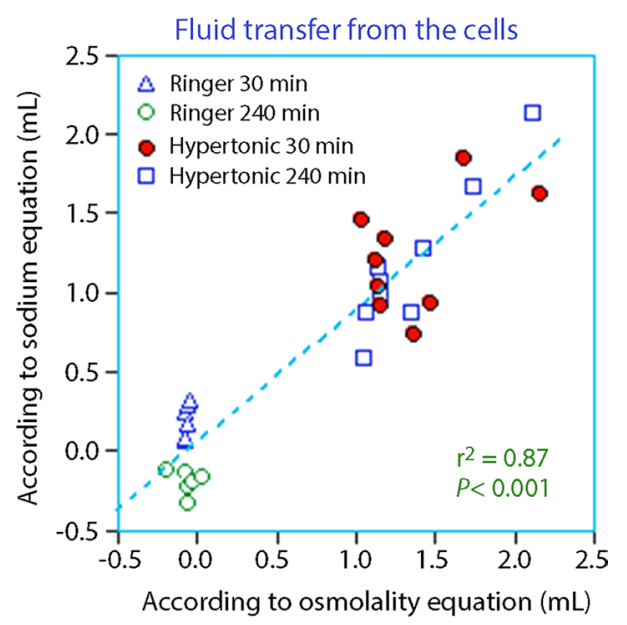

Fig. 1 Calculation of the recruitment of fluid from the ICV to the ECV at $30 \mathrm{~min}$ and $240 \mathrm{~min}$ after infusion of Ringer's solution and hypertonic saline in volunteers. Each point is one measurement (two in each volunteer). No correction for urinary excretion was performed

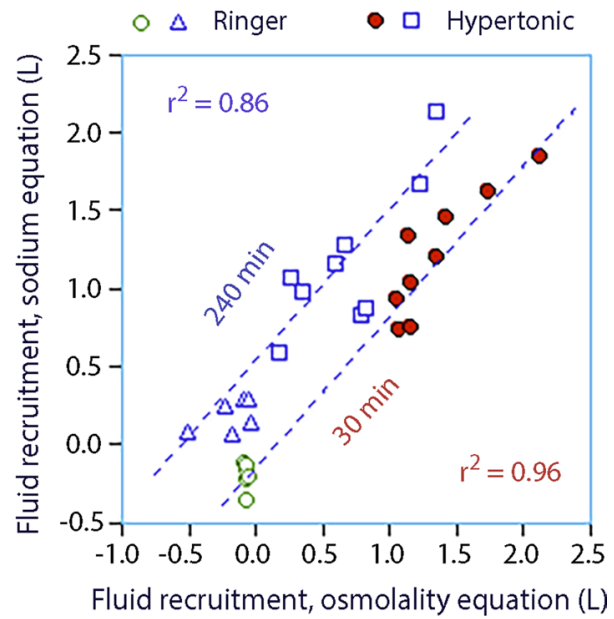

Fig. 2 Same plot as Fig. 1 but with correction of excreted fluid, sodium and osmolality at 240 min. Such data were not available at $30 \mathrm{~min}$. The left displacement of the curve at $240 \mathrm{~min}$ as compared to Fig. 1 shows the influence of urinary excretion on the results

\section{Simulation of fluid exchange with altered body fluid volumes}

The following simulations aimed to examine whether the solute data best agreed with ECV and ICV volumes as measured by the BIA or by the commonly reported "textbook" fractions of $20 \%$ and $40 \%$ of the BW.

The sodium and osmolality equations were then used to simulate the transcellular fluid shift based on changes of assumed ECV and ICV volumes in steps of $10 \%$ between 50 and $130 \%$ of the "textbook" fractions. These simulations showed that the ECV but not the ICV greatly affected the calculated fluid shift (Fig. 3A, B).

As reported above, the osmolality equation indicated that $694 \mathrm{~mL}$ of intracellular fluid had been recruited at $240 \mathrm{~min}$ in hypertonic group when ICV was set to $40 \%$ of the BW. The same fluid shift would be obtained by the sodium equation if the ECV 


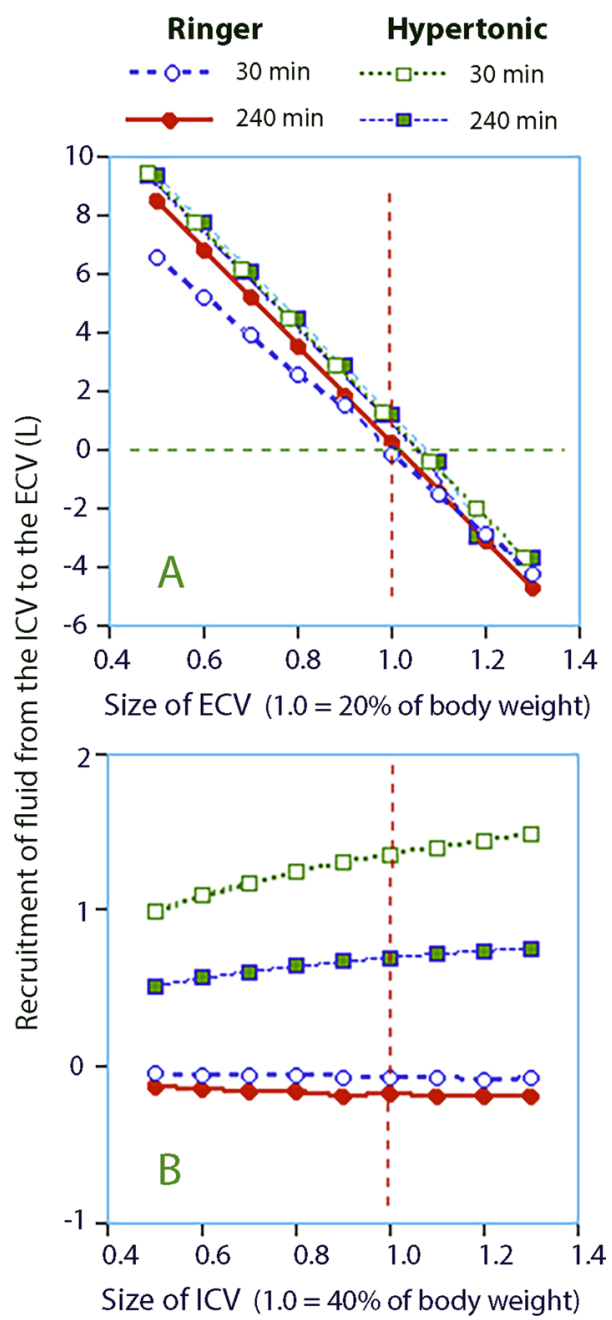

Fig. 3 Transfer of fluid from the ICV to the ECV as estimated by the $\mathbf{A}$ Sodium equation and $\mathbf{B}$ Osmolality equation. The data points were obtained by setting ECV and ICV to arbitrary volumes that deviate from the "textbook" fractions of $20 \%$ and $40 \%$ of the body weight with a factor

had been $20.6 \%$ of the BW. With that ECV size, the fluid recruitment of hypertonic fluid became virtually identical at $688 \mathrm{~mL}$.

On setting the ECV to 1.2 (25\% of BW) in the sodium equation (Fig. 3A) the fluid exchange in Ringer and hypertonic groups indicate that approximately $3 \mathrm{~L}$ of fluid would be transferred from the ECV to the ICV, i.e., in the direction being contrary to the expected one. Therefore, according to our simulation, the BIA did not provide a truthful estimate of the ECV.

Deliberate changes of the ICV in the osmolality equation resulted in much smaller variations of the fluid translocation (during this simulation, the ECV was maintained at $20 \%$ of the BW, Fig. 3B). The slope obtained by assuming different values of ICV was not steep enough for reaching a reasonably firm conclusion about the size of the ICV. Instead, we plotted the osmolar balance at $240 \mathrm{~min}$ versus the change in serum osmolality for the hypertonic infusions to obtain a figure of the size of the ICV. This regression showed that adding 600 mosmol to the body corresponded to a rise in serum osmolality 
of $13.8 \mathrm{mosmol} / \mathrm{kg}$ (Fig. 4). The volume of distribution of the administered osmolality was then $600 / 13.8=43.5 \mathrm{~L}$. The body weight of these volunteers averaged $82 \mathrm{~kg}$, which yields that the total body water occupied $53 \%$ of the BW. With an ECV volume being $20 \%$ of the body weight the size of the ICV was $33 \%$ of the BW, or $27 \mathrm{~L}$.

\section{Discussion}

\section{Key result}

Our results illustrate that solute equations can be applied after an infusion of isotonic or hypertonic fluid to ascertain whether assumed or measured ECV is reasonable from a physiological point of view. The osmolality equation tells us that Ringer's should translocate only very minor amounts of water across the cell membrane. However, using the solute equations with an ECV that differs that from the "textbook" value it would imply that a large transfer of water in and out of the ECV occurs, which we know is not the case (Fig. 3A). The law of osmolality also tells us that hypertonic saline translocates water from the ICV to the ECV assuming textbook fluid compartments. Nevertheless when the solute equations are used they indicate a flow from ECV to ICV if we apply the BIA-derived ECV, which is an aberrant fluid dynamic.

The precise volumes may be modified by urinary excretion and solutes and fluid, but our calculations show that dramatically different flows are predicted if the ECV is changed. By contrast, the solute equations proved less useful to ascertain whether a reported ICV is reasonable.

\section{Transcellular recruitment of water}

The transcellular transport of fluid as indicated by of one sodium and one osmolality equation was calculated in a young volunteer population given an infusion of hypertonic or isotonic crystalloid infusion. Both equations yielded similar mean values for transcellular transport of water when the ECV and ICV were set to the "textbook" volumes. The Ringer infusions caused only minor changes of intracellular water, while hypertonic fluid

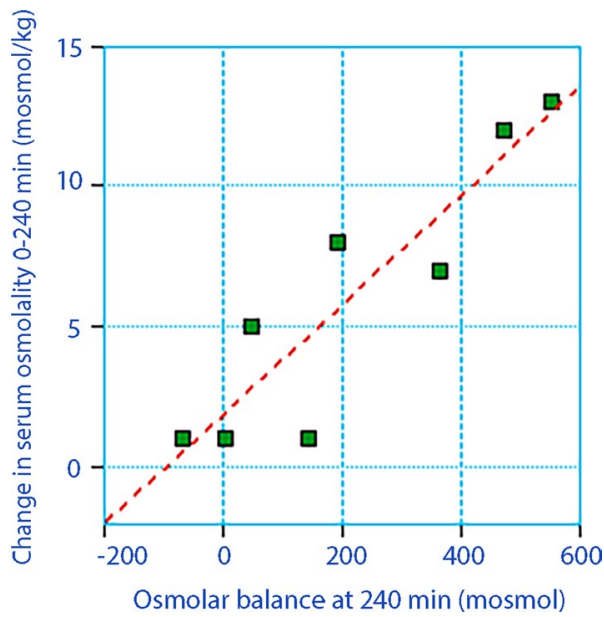

Fig. 4 Osmolar balance (= difference between the infused and excreted osmolality) versus the increase in serum osmolality in the hypertonic group. One extreme outlier is not shown. The Total Body Water (= sum of $\mathrm{ECV}$ and ICV) is calculated as $x / y$ 
withdrew more than $1 \mathrm{~L}$ from the ICV, which represents approximately 4.5 times the infused volume of $7.5 \%$ saline. One could perhaps expect 7.5 times the infused volume would be withdrawn, but more pronounced transcellular allocation of water is counteracted by concentration of the intracellular electrolytes.

No data on the urinary excretion was obtained at $30 \mathrm{~min}$, but losses of electrolytes and water were probably quite small at that time. Complete data was only available at $240 \mathrm{~min}$. Then calculations then disclosed a left-sided displacement of the fluid recruitment curve as evidence that some fluid had already returned to the ICV (cf. Figs. 1 and 2).

\section{The ECV volume}

Our results suggest that calculations based on solute changes can be used to examine how realistic a reported ECV volume is. Logical transcellular fluid shifts were obtained when the ECV was set to the "textbook volumes" being 20\% of BW for the ECV and the $40 \%$ of the BW for the ICV. However, the simulation using the BIA-derived size the ECV is highly unlikely to be correct. Being $25 \%$ of the BW would mean that several liters of fluid enters the ICV when hypertonic saline is infused (Fig. 3A). The law of osmolality rather tells us that hypertonic saline recruits fluid from the ICV, and not the opposite.

We have previously pointed out that the ECV and ICV measured with BIA disagrees with these commonly accepted "textbook" volumes, although it has been unclear which one is most correct [7]. The BIA volumes we reported here, suggesting that the ECV accounted for $25 \%$ of the BW and that the ICV accounted for $22 \%$ of the body weight, are not unique but reasonably in line with previously published data $[4-6,8-11,14]$. However, our present data support that the "textbook" ECV is the more likely to be correct than the BIA values.

\section{The ICV volume}

Our results further show that calculations based on solute changes cannot be used to examine how realistic a reported ICV volume is using the same reasoning as for the ECV volume. The size of the ICV could not be adequately assessed by the osmolality equation. However, a regression plot comparing the osmolar balance and the change in serum osmolality yielded more clear information. This plot indicated that the ICV amounted to $33 \%$ of the BW (Fig. 4). Hence, the osmolality still obtained an ICV that was smaller than the conventionally assumed $40 \%$ of the BW, although not as small as the volume obtained with the BIA method.

\section{Why do the volumes differ?}

There may be several explanations to the difference in body fluid volumes between the textbooks and the more recently obtained BIA values. One is that the ICV, and to some degree the ECV, depends on the daily water intake as indicated by urinary biomarkers; a low intake is associated with a larger ICV and a high daily intake, resulting in more diluted urine, with a smaller ICV [12]. The large "textbook" size of the ICV might then have been derived from a cohort with a low daily intake of water. However, our present study does not support that view as measurements from the same individuals were compared. The electrolyte data 
suggest that that the size of ECV is likely to have been approximately $20 \%$ rather than $25 \%$, while the ICV is probably somewhat lower than $40 \%$, even in young men.

Alternatively, the radioisotope measurements used to create the computer program that converts the BIA spectral signals to ECV and ICV for the widely used Xitron spectroscope may have been interpreted erroneously. The original study used for this purpose measured the ECV with bromide and arrive at $24.5 \%$ of the BW [5], which is $5 \%$ higher than our results with the same method [16]. The authors deliberately allowed BIA to underestimate the ICV as indicated by deuterium by as much as $7 \mathrm{~L}$, because they relied more on measuring ICV by radioactive potassium [5]. In the present study, we found the difference between BIA and the ICV indicated by our electrolyte calculations to be the same at 7.4 L. This suggests that the deuterium volume instead of the radioactive potassium volume might have been more appropriate to used for transforming the BIA signals to volumes.

\section{Literature}

The BIA literature has caused uncertainty about the sizes of the body fluid compartments. Several previously published studies using BIA report fractions higher than the commonly accepted $20 \%$ of the BW for ECV and markedly lower fractions than $40 \%$ for the ICV. These results seem to be in line with findings in this study with ECV accounting for $25 \%$ of BW and ICV for $22 \%$ of BW of BW (Table 1 ).

When applying BIA in males, Ohashi et al. found the ECV to be $22.4 \%$ of the BW [11], while in women showed to be approximately $22 \%$ [12]. Other studies have also reported ECV volumes several percentages higher than $20 \%[8,10,17]$ and the ICV to be around $20 \%$ of the BW $[7,8,18]$.

Old studies using dilution-indicators techniques report body fluid volumes that agree better with the "textbook volumes" than the more recent BIA literature [2, 3, 19]. One study in volunteers from 2005 yielded $18.3 \%$ of the BW when estimating the ECV by sodium dilution, $19.6 \%$ by iohexol dilution, and $20.5 \%$ by bromide [16].

The presence of fractions of structured water may possibly explain differences on measuring body compartments with different methods [20,21]. Norberg et al. used ethanol and deuterium oxide to calculate TBW and found a bias of $-12.6 \%$ which the authors explained as being due to measurement of different water spaces [19].

Sodium might the stored in non-osmotic form when given in a large surplus. Engberink et al. showed that only $47 \%$ of the sodium and $55 \%$ of the potassium could be recovered in the urine $4 \mathrm{~h}$ after infusion of hypertonic saline in 12 healthy volunteers [22]. Possible structures for accumulation of the non-osmotic sodium might be the glycosaminoglycans present in skin, bones and cartilages. However, the time frame for the conversion of ionic to non-ionic sodium is unclear. Our data confirms that $50 \%$ of the infused sodium is recovered in the urine after $4 \mathrm{~h}$ but interpreted the remaining sodium as an osmotic force that recruited fluid from the ICV, which by itself diluted the plasma sodium level.

\section{Limitations}

The sample size was relatively small and did not include females, who are known to have a different water composition than men. A surgical population of elderly patients with comorbidities could also have had different body fluid composition and fluids [23, 24]. 
Some of the hypertonic infusions contained dextran, which redistributes fluid from the interstitial fluid space to the plasma. However, the osmolality due to the colloid component is negligible, leaving almost no room for additional redistribution of fluid across the cell membrane.

\section{Conclusions}

Mass balance calculations based on whole-body equilibriums of solutes after intravenous infusion of isotonic and hypertonic fluid show that the estimated water exchange across the cell membrane is incompatible with the size of the ECV obtained by Xitron BIA. By contrast, the same calculations agree well with the ECV volume amounting to $20 \%$ of the body weight which is commonly reported in medical textbooks.

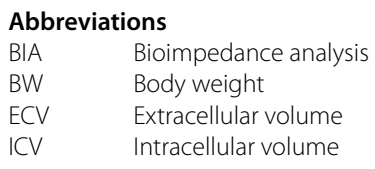

\section{Acknowledgements}

Not applicable.

Authors' contributions

All authors contributed to the study conception and design. $\mathrm{RH}$ conducted experiments. $\mathrm{RH}$ and MGM analyzed the data. $\mathrm{RH}$ and MGM wrote the manuscript. Both authors read and approved the final manuscript.

\section{Funding}

Open access funding provided by Karolinska Institute. No funding was sought for development of this study.

Availability of data and materials

Data can be available on request.

\section{Declarations}

Ethics approval and consent to participate

The protocols had been approved by the Ethics Committee of Huddinge University Hospital (Dnr 228/98 and 54/95, Chairmen Ola Eiken and Lennart Kaijser) $[14,15]$. Informed consent was obtained from all participants.

\section{Consent for publication}

Informed consent was obtained from all participants.

\section{Competing interests}

The authors have no competing interests to declare that are relevant to the content of this article.

Received: 10 December 2021 Accepted: 1 March 2022

Published online: 07 March 2022

\section{References}

1. Chambers D, Huang C, Matthews G (2019) Basic physiology for anaesthetists, 2nd edn. Cambridge University Press, Cambridge, p 318

2. Schloerb PR, Friis-Hansen BJ, Edelman IS, Solomon AK, Moore FD (1950) The measurement of total body water in the human subject by deuterium oxide dilution; with a consideration of the dynamics of deuterium distribution. J Clin Invest 29:1296-1310

3. Lavietes PH, Bourdillon J, Klinghoffer KA (1936) The volume of the extracellular fluids of the body. J Clin Invest 15:261-268

4. Hannan WJ, Cowen SJ, Fearon KC, Plester CE, Falconer JS, Richardson RA (1994) Evaluation of multi-frequency bioimpedance analysis for the assessment of extracellular and total body water in surgical patients. Clin Sci 86:479-485

5. de Lorenzo A, Andreoli A, Matthie J, Withers P (1997) Predicting body cell mass with bioimpedance by using theoretical methods. J Appl Physiol 82:1542-1558

6. Simpson JAD, Lobo DN, Anderson JA, MacDonald IA, Perkins AC, Neal KR, Allison SP, Rowlands BJ (2001) Body water compartment measurements: a comparison of bioelectrical impedance analysis with tritium and sodium bromide dilution techniques. Clin Nutr 20:339-343 
7. Hahn RG, Giménez-Milà M (2021) The intracellular fluid compartment is smaller than commonly believed when measured by whole-body bioimpedance. J Basic Clin Physiol Pharmacol. https://doi.org/10.1515/jbcpp-2021-0022

8. Zhu F, Abbas SR, Kotanko P, Levin NW (2017) Effect of age and blood pressure on determination of normal fluid status in a general population using whole body and calf bioimpedance techniques. Physiol Meas 38:1289-1300

9. Matias CN, Judice PB, Santos DA, Magalhaes JP, Minderico CS, Fields DA, Sardinha LB, Silva AM (2016) Suitability of bioelectrical based methods to assess water compartments in recreational and elite athletes. J Am Coll Nutr 35:413-421

10. Ernstbrunner M, Kostner L, Kimberger $O$ et al (2014) Bioimpedance spectroscopy for assessment of volume status in patients before and after general anaesthesia. PLoS ONE 10:e111139

11. Ohasi Y, Joki N, Yamazaki K, Kawamura T, Tai R, Oguchi H, Yuasa R, Sakai K (2018) Changes in the fluid volume balance between intra- and extracellular water in a sample of Japanese adults aged 15-88 yr old: a cross-sectional study. Am J Physiol Renal Physiol 314:F614-F622

12. Hahn RG (2021) Effects of diet, habitual water intake and increased hydration on body fluid volumes and urinary analysis of renal fluid retention in healthy volunteers. Eur J Nutr 60:691-702

13. Hahn RG, Drobin D (2003) Rapid water and slow sodium excretion of Ringer's solution dehydrates cells. Anesth Analg 97:1590-1594

14. Drobin D, Hahn RG (2002) Kinetics of isotonic and hypertonic plasma volume expanders. Anesthesiology 96:1371-1380

15. Drobin D, Hahn RG (1999) Volume kinetics of Ringer's solution in hypovolemic volunteers. Anesthesiology 90:81-91

16. Zdolsek J, Lisander B, Hahn RG (2005) Measuring the size of the extracellular space using bromide, iohexol and sodium dilution. Anesth Analg 101:1770-1777

17. Matias CN, Judice PB, Santos DA, Magalhaes JP, Mindreico CS, Fields DA, Sardinha LB, Silva AM (2016) Suitability of bioelectrical based methods to assess water compartments in recreational and elite athletes. J Am Coll Nutr 35:413-421

18. Van Loan MD, Mayclin PL (1992) Use of multi-frequency bioelectrical impedance analysis for the estimation of extracellular fluid. Eur J Clin Nutr 46:117-124

19. Norberg Å, Sandhagen B, Bratteby L-E, Gabrielsson J, Jones AW, Fan H, Hahn RG (2001) Do ethanol and deuterium oxide distribute into the same water space in healthy volunteers? Alcohol Clin Exp Res 25:1423-1430

20. Israelachvili J, Wennerström H (1996) Role of hydration and water structure in biological and colloidal interactions. Nature 379:219-225

21. Cameron IL, Kanal KM, Keener CR, Fullerton GD (1997) A mechanistic view of the nonideal osmotic and motional behavior of intracellular water. Cell Biol Int 21:99-113

22. Olde Engberink RHG, Rorije NMG, van den Born BJH, Voigt L (2017) Quantification of nonosmotic sodium storage capacity following acute hypertonic saline infusion in healthy individuals. Kidney Int 91:738-745

23. Söderberg M, Hahn RG, Cederholm T (2001) Bioelectrical impedance analysis of acute body water changes in congestive heart failure. Scand J Lab Invest 61:89-94

24. Oya S, Yamashita H, Iwata R, Kawasaki K, Tanabe A, Yagi K, Aikou S, Seto Y (2019) Perioperative fluid dynamics evaluated by bioelectrical impedance analysis predict infectious surgical complications after esophagectomy. BMC Surg 19:184

\section{Publisher's Note}

Springer Nature remains neutral with regard to jurisdictional claims in published maps and institutional affiliations.

\section{Submit your manuscript to a SpringerOpen ${ }^{\circ}$ journal and benefit from:}

- Convenient online submission

- Rigorous peer review

- Open access: articles freely available online

- High visibility within the field

- Retaining the copyright to your article

Submit your next manuscript at $\gg$ springeropen.com 